\title{
Deus televisivo da IURD Análise de um programa-modelo para a corrente Neopentecostal
}

Resumo:A cada ano as igrejas neopentecostais ocupam mais espaço na programação televisiva nacional. A IURD (Igreja Universal do Reino de Deus), que iniciou suas atividades em 1977, fez escola e é considerada como uma instituição religiosa-modelo pelas igrejas dessa corrente religiosa no que se refere à exploração do espaço televisivo para a adesão de fiéis. Neste texto, o autor analisa um programa televisivo desta igreja, revelando o alto grau de profissionalismo na construção de discurso e na utilização dos recursos audiovisuais da televisão.

Palavras-chave: programa; televisão; religião; neopentecostalismo; IURD

\begin{abstract}
Each year the churches neopentecostais occupy more space in national television programming. The IURD (Universal Church of the Kingdom of God), which began in 1977, has school and is regarded as a religious institution-model for churches that current religious regarding the operation of the television space for membership of believers. In this text, the author analyzes a television programme this church, showing the high degree of professionalism in the construction of speech and resource use of audiovisual television.
\end{abstract}

1 Bacharel em Comunicação Social Relações Públicas (Unicap), especialista em Educação em Valores (Universitat de Barcelona) e em Psicologia na Comunicação (Puc-RS), mestre em Ciências da Comunicação (Universidade Católica Portuguesa) e doutorando em Comunicação e Poder (Universidad de Málaga). É autor de quatro E-books com livre distribuição na Internet e de dois livros sobre a atuação das igrejas neopentecostais na televisão brasileira: "Dinheiro: passaporte para a graça" (2006) e "Neopentecostais e Mediações Culturais" (2007). Atualmente leciona no Recife.. 


\section{Introdução}

Comunicação e religião sempre estiveram lado a lado desde os primórdios da humanidade, pois enquanto o ato de se comunicar é "a base existencial de toda sociabilidade" (UNESCO,1983: 5), a religião, seja qual for, nunca é falsa, pois é totalmente social (DURKHEIM, 2003).

Entretanto, desde o início dos anos 90 o (perplexo) meio acadêmico passou a discutir o aumento do número de pessoas que aderiram às chamadas igrejas neopentecostais, sobretudo pelo fato do Brasil ser um país tradicionalmente católico. Surgido no final da década de $70 \mathbf{2}$, o neopentecostalismo - que representa a terceira fase da implantação das igrejas pentecostais no Brasil e é caracterizado por um forte discurso populista, centrado na Teologia da Prosperidade $\mathbf{3}$ - passou a fazer parte da vida cotidiana dos bairros e concentrações urbanas mais pobres, introduzindo em seus cultos elementos culturais das mais diversas representações sociais, além de oferecer soluções práticas e imediatas para os sofrimentos expressados pela população.

O êxito alcançado por estas instituições está ligado diretamente ao seu audacioso projeto de evangelização baseado na seguinte idéia: no horário comercial e noite, a evangelização deve acontecer nos templos físicos espalhados por todo país, enquanto as igrejas eletrônicas (ASSMANN, 1986) fazem esse papel no horário de ócio do fiel.

A consolidação desta agressiva estratégia (comercial) das igrejas neopentecostais se deu no final da década de 80 , quando a instituição de maior representatividade entre os fiéis, a Igreja Universal do Reino de Deus, adquire a Rede Record de Televisão e inicia uma corrida pela audiência religiosa na televisão brasileira, culminando em dezenas de programas que passam a ser transmitidos em praticamente todos os horários. A aquisição da Record fez com que não só a IURD como todas as ramificações neopentecostais passassem a valorizar mais o templo eletrônico do que os próprios templos tradicionais, concordando com a premissa barberiana de que a ausência de uma cultura letrada tornou o nosso povo iminentemente audiovisual (MARTÍN-BARBERO; REY, 2001).

Sobre este projeto midiático da IURD, ROCHA (1998: 125) afirma que o projeto é manter as igrejas abertas até à meia-noite. A partir daí o "trabalho de assistência espiritual" permanente aos fiéis é feito em programas ao vivo, até às oito horas da manha, como Palavra da Vida, Jesus verdade e Despertar da fé.

A iniciativa da IURD em adquirir um canal de televisão e especializar-se na

Época em que se consolidava a ndustrialização e o crescimento urbano no país e se iniciava um processo de modernização nas comunicações.

\section{3} conjunto de princípios que firma que o cristão verdadeiro tem o direito de obter a felicidade integral e de exigi-la ainda durante a vida presente sobre a terra, bastando para isso que tenha confiança incondicional em Jesus. Na busca da bênção, o fiel deve determinar, decretar, reivindicar e exigir de Deus que Ele cumpra sua parte no acordo: ao fiel compete dar dízimos e ofertas; a Deus cabe abençoar.

Rede Vida, que iniciou suas transmissões em $1 \stackrel{\circ}{\circ}$ de fevereiro de 1995. Mais informações em www.redevida.com.br. arte de tele-evangelizar teve um impacto tão significativo entre o público que a Igreja Católica, denominação religiosa hegemônica no país e que sempre teve profundas resistências à difusão de sua doutrina pelos meios de comunicação de massa, criou um canal próprio $\mathbf{4}$ de variedades para fazer frente a essa concorrência e conter o avanço das igrejas neopentecostais.

O inicial desprezo da Igreja Católica às práticas midiáticas dos neopentecostais, ao que parece, custou caro à Santa Igreja: as igrejas neopentecostais se solidificaram no ambiente religioso nacional à custa da falta de visão global do clero católico. Mas, que tipo de programação televisiva é esta que consegue estremecer as bases da milenar Igreja Católica? Que estratégias utilizam? $\bigcirc$ que dizem?

Este breve texto analisará um programa vespertino da IURD $\mathbf{5}$, considerado como um programa-modelo para as demais instituições neopentecostais (e por que não católicas?), que alcançam visibilidade social ao seguir estritamente o script iurdiano. 
O programa começa com uma cena em que a tela da televisão passa a ter um aspecto de janela de avião, fazendo com que o telespectador (ao olhar a tela) se sinta flutuando sobre um céu azul anil repleto de nuvens. Do fundo dessas nuvens aparece um coração vermelho com uma pomba da paz no centro - a marca da IURD. Esta marca, na verdade, se tornou um ícone entre os adeptos desta igreja, já que consegue representar toda carga ideologia iurdiana para seus simpatizantes. Baseando-se no que diz HOLT (2005), o sucesso da marca-ícone da IURD está na exploração, espoliação do mito que está por trás desta marca (leia-se Edir Macedo), com um grande número de repetições nos programas e exibições em todo o espaço físico utilizado pela igreja. Esta prática iurdiana nos faz recordar uma lição do execrável ministro da propaganda do Terceiro Reich, Joseph Goebbels, que afirmava que "uma mentira repetida inúmeras vezes se torna uma verdade" (MARÇAL NETO, 2003: 55).

Após a abertura do programa, dizeres bíblicos surgem na tela e, com um assustador estrondo, é anunciado o dia 16 de Janeiro como um dia santo: o dia da última "Fogueira Santa de Israel", em que as pessoas depositarão pedidos numa cúpula, em que, segundo os pastores $\mathbf{6}$, serão levados para Israel. A cúpula - uma adaptação cenográfica do templo de Salomão, com um altar para os sacrifícios - é mostrada detalhadamente por um dos pastores que, inclusive, está com vestes antigas em vermelho e dourado, com o símbolo do Knesset israelita no peito. Esta apropriação de elementos de outras religiões, uma das características mais marcantes do sincrético culto iurdiano é, de acordo com OLIVEIRA, uma forma de tornar os adeptos "sujeitos ativos da evangelização e não meros receptores de uma mensagem produzida num contexto cultural que fuja a sua compreensão" (2004: 29). Com isso, a IURD faz com que as pessoas se sintam parte daquele "reino dos céus", não apenas expectadores de milagres de terceiros.

Interessante é perceber que desde o início do programa os pastores informam o horário - para provar que estão transmitindo o programa ao vivo - e que estão se sacrificando em forma de jejum. Alegam, ainda, que aquele sofrimento pelo qual estão passando - no caso, a fome - é pelas pessoas que os estão assistindo, pelos fiéis, seguindo o exemplo de Cristo, que sofreu pelos pecados da humanidade.

\section{As vinhetas temáticas}

Após os pastores pedirem permissão para se ausentar e avisarem que logo retornariam, vinhetas temáticas ligadas à história bíblica de Gideão $\mathbf{Z}$ são mostradas. Cenas fortes de um filme bíblico são exibidas durante vários minutos, tendo como fundo uma voz grave - com um efeito de profundidade - anunciando o milagre que Deus operou na vida dos israelitas naquele remoto tempo.

Entretanto, este milagre parece ter preço, segundo os dizeres bíblicos anunciados na tela:

6 Interessante constatar que os pastores também apresentam os programas televisivos, o que se supõe que recebam treinamento profissional para desempenhar tal trabalho.

7 Gideão foi o quinto dos juízes ou libertadores, apresentado em Juízes, capítulos 6, 7 e 8 .

\section{"Gideão disse-lhes: "Nem eu reinarei sobre vós, nem meu filho reinará sobre vós. É o Senhor que reinará sobre vós". E acrescentou: "gostaria de fazer-vos um pedido: que cada um de vós me dê o anel de seu butim”. (É que os vencidos, por serem ismaelitas, tinham anéis de ouro.) Eles responderam: "Daremos com prazer!"Estenderam um manto e cada um jogou ali o anel de seu butim”.}

Imagens de sofrimento, guerra e sangue são mostradas, mas, logo após o letreiro desaparecer da tela, surgem imagens que parecem ser já do final do filme, em que se vêem pessoas sorrindo, comendo fartamente e ornamentadas com 
muitos brilhantes e ouro, significando fartura material. Este passeio dantesco das imagens, do inferno ao paraíso, coincide com um dos slogans mais usados pela igreja, que se refere exatamente a esta capacidade divina de se alcançar a graça em pouco tempo: "Venha para a Igreja Universal, onde o milagre é uma coisa natural" (MACHADO, 2004).

\section{Os pastores que apresentam os programas}

A imagem do filme dá lugar à imagem de um pastor usando uma camisa negra com o letreiro em branco dizendo "Sou de Gideão: a obediência vence o medo!". Dois pastores - um, vestido com uma camisa esportiva com os letreiros descritos acima, e outro, com um manto parecidíssimo com o que o personagem bíblico usava no filme - fazem a seguinte pergunta: "nós passamos toda tarde e noite aqui. Onde está o teu pastor agora? Onde ele está de madrugada?" Nós não te abandonamos!"”.

Nota-se no discurso do pastor uma profunda falta de ecumenismo religioso, que pode ser identificada em todos os eventos, não só da IURD como de todas as igrejas neopentecostais. Além de criarem uma espécie de fronteira imaginária, em que os membros da igreja se consideram "escolhidos" (MACHADO, 2004), há uma grande tendência a demonizar o inimigo, isto é, as pessoas que não professam a mesma fé que eles. $\mathrm{ORO}$, que considera estas práticas tipicamente de grupos fundamentalistas, afirma que estes grupos religiosos "colocam-se em oposição aos outros, mesmo cristãos, por não viverem radicalmente, ou melhor, literalmente, os axiomas da fé, e em oposição às maiorias sociais" (1996:127).

Na seqüência do programa, os pastores continuam a discutir entre si o porquê de eles não terem doenças, não sofrerem moléstias e não sentirem sono, mesmo estando a mais de 48 horas sem dormir. Um dos pastores, aos gritos, pergunta o que eles - homens casados e com filhos - estão fazendo na igreja há mais de uma semana. $O$ pastor com vestes milenares olha para a tela, sorri, e diz: "Por causa de vocês, irmãos, que estão doentes, desempregados, sem esperança".

A postura dos pastores é despojada, natural, exceto quando falam dos temas cura, exorcismo e libertação. É explícito o fato de eles imitarem a tonalidade e forma com que o bispo Edir Macedo fala a seus fiéis. Fechando os olhos, um telespectador, talvez, não consiga identificar se aquele se trata de Edir Macedo ou não. JUSTINO (2002), em seu livro-denúncia, disse que os pastores chegam a disputar entre si o status de quem melhor imita o seu líder. Um jovem pastor, inclusive, chega a ser chamado de "Macedinho" pelos colegas, por imitar até o defeito físico que o bispo Macedo possui desde seu nascimento.

Um outro pastor aparece diante da tela, com uma camisa negra com os dizeres "Eu estou indignado, você?" em branco. Ele fala do que Deus espera de um homem e segura um pergaminho da Torá $\boldsymbol{8}$ com frases escritas em alfabeto hebraico. No canto inferior da tela, um letreiro passa anunciando os horários das cerimônias e o endereço do Templo Maior da Fé. Outro anúncio interessante é o do chamado "S.O.S. espiritual". Segundo os apresentadores, há alguém ungido pelo Senhor atrás do telefone sabendo exatamente do que sofre aquele crente que liga.

\section{A questão do dízimo e das ofertas}

Os problemas financeiros são apresentados como uma das problemáticas centrais de todo o programa. Vale salientar que existe até um bloco específico para empresários que se encontram com suas finanças falidas.

Como já foi dito, dizeres bíblicos que legitimam o ato de dizimar mensalmente dez por cento de todo o dinheiro que o trabalhador ganha são 
incessantemente mostrados na tela, sendo que o não cumprimento desta suposta ordem divina é apresentado como afronta a Deus. Segundo os apresentadores, as mazelas sociais que o povo brasileiro sofre - desemprego, violência urbana e rural, saúde precária, analfabetismo - são castigos que provêm, justamente, da falta de compromisso com Deus, ou seja, a falta do pagamento material.

Sobre o ato de dizimar, o pastor indaga ao telespectador:

\footnotetext{
"Deus vai te dar a cura; vai curar tuas feridas; vai te dar emprego; vai libertar teu marido do álcool; vai livrar teu filho da droga; vai curar teu câncer e tua AIDS; vai te libertar das garras de Satanás. Você acha que isso tem preço? $\bigcirc$ teu dízimo é uma ordem divina, não um agrado".
}

Para destacar o papel de quem tem um compromisso mensal de dar dez por cento do seu salário à igreja, esta criou uma espécie de hierarquia dentro das cerimônias, em que só os dizimistas podem participar. Além do dízimo, a oferta é bastante motivada pelos apresentadores, que a colocam da seguinte maneira:

\footnotetext{
“A oferta é um presente que se dá a Deus de coração. Deus só se materializa no fogo, só faz milagre no fogo. Então, traz tua oferta de coração que a colocaremos neste altar e queimaremos o sacrifício como os israelitas queimavam os bezerros para adorar Deus".
}

No altar mostrado na televisão, se vêem objetos de valor comercial, como pulseiras e cordões de ouro e prata, envelopes com algumas notas de dinheiro à mostra e cheques. Este grande apelo ao dinheiro, fruto da influência decisiva da Teologia da Prosperidade na elaboração de toda liturgia iurdiana, é explicada por DANTAS (2006: 27), que afirma que o avanço do mercado fez com que a religião se submetesse às suas leis e se transformasse numa mercadoria específica cuja comercialização, em sua essência, não difere de outras mercadorias. Essa lógica de mercado fez com que a religião se tornasse um mero produto comercial em busca da lucratividade no comércio dos bens simbólicos.

\section{As testemunhas de milagres}

As testemunhas são mostradas a cada discurso temático dos pastores, com o objetivo de legitimar e sustentar o que acabou de ser dito. Antes do testemunho uma voz ecoa os seguintes dizeres: "Se você está triste, venha à nossa família. Você que se sente tão só - Igreja Universal do Reino de Deus: um universo, um mundo só de amor".

Sempre pessoas com um nível educacional acima da média brasileira são mostradas como exemplo, e seus testemunhos ganham vida com fundo musical, efeitos sonoros e imagens externas. Como introdução ao depoimento a ser veiculado, um pastor diz: "Assista agora à intervenção de Deus na vida daqueles que participaram da Semana Santa de Israel, na Fé de Gideão".

Um exemplo de testemunho foi a entrevista feita com um médico que descreve seu início de carreira brilhante. Segundo ele, era muito jovem, começou sua vida profissional já ganhando muito dinheiro - R\$9.000,00 -, mas que não se importava com a questão espiritual. $\bigcirc$ único prazer que lhe dava era gastar dinheiro e ostentar seus bens em público.

Entretanto, não durou muito para que sua vida financeira fosse arrasada por dívidas contraídas pelos cartões de crédito, fazendo com que sua saúde e família se desestabilizassem. Como conseqüência, perdeu todos os aparelhos clínicos e não tinha mais condições de pagar o aluguel da clínica. 
Porém, após ter participado da "Vigília dos 318", o Doutor 9 começa a reerguer-se e depois de um ano já possui quatro clínicas de diagnóstico, algo que nenhum dos seus colegas de faculdade logrou até hoje.

Para justificar o seu sucesso, o jovem médico afirma:

\begin{abstract}
“Deus é meu sócio. Vejo Deus tanto nos bens que adquiro quanto nos pacientes que atendo. A minha vida mudou não somente na questão financeira, mas minha pessoa também. Mas, irmãos, não é chegando na vigília que se muda. Não! Deve-se escutar os homens de Deus e endireitar os caminhos. É preciso fé, perseverança e humildade”.
\end{abstract}

Os testemunhos possuem muita importância nos programas da IURD, pois, mesmo que o telespectador não tenha vivenciado o drama descrito pela testemunha, no programa, ele é levado a colocar-se no lugar daquela pessoa, e isso o influencia de alguma forma, como afirma MACHADO (2004: 60):

Eu posso, assistindo os testemunhos, discordar, questionar e duvidar mas, ainda assim, eu sei do que eles estão falando, reconheço as angústias e os desejos movem os depoentes no interior da procura pelo sagrado e dos limites deste discurso".

\title{
As histórias moralistas
}

Uma das produções mais bem feitas, apresentada no programa, são as histórias que contam alguma desgraça vivida por aqueles que não estão "protegidos" pelas orações da IURD. Antes de apresentar a história, todo um mistério é criado pelo apresentador, fazendo com que o telespectador fique apreensivo.

Numa das histórias apresentadas, a trama começa com duas amigas no trabalho conversando alegremente. $O$ papo informal e divertido é interrompido pelo chefe, que indaga à personagem Fernanda sobre o péssimo rendimento apresentado. Karina, sua amiga, intervém e diz ao chefe que ajudará sua amiga a superar seus problemas. Voltando para casa, Fernanda sente-se triste e liga para uma outra amiga. Esta, por sua vez, indica uma Mãe de Santo muito boa, que pode ajudá-la. Logo, Karina chega, as duas se abraçam, começam a provar roupas diante do espelho e saem para se divertir.

Entretanto, no retorno, a inveja toma conta de Fernanda, e esta passa a refletir numa forma de tomar o posto de trabalho de Karina. Logo, lembra da sugestão da sua outra amiga e resolve visitar o terreiro. Ao chegar ali, Fernanda oferece seus pertences em troca de um trabalho de feitiçaria que promova a queda de Karina e sua promoção ao cargo na empresa.

Logo são mostradas as duas chegando juntas, bem cedo, ao trabalho, e Fernanda dá de presente uma caixa de chocolate a Karina. Esta caixa, na verdade, está enfeitiçada, e ao comer o chocolate Karina começa a ter seu desempenho comprometido, bem como seu ânimo.

Novamente, o chefe convoca as duas funcionárias para novas considerações e indaga a Karina que em vinte anos de empresa nunca a viu com um desempenho tão ruim. Ele Ihe dá um ultimato: ou ela melhora o desempenho, ou ele terá que tomar medidas. Ao mesmo tempo, exalta o trabalho demonstrado por Fernanda.

Passados alguns dias, o chefe volta a convocá-las e parabeniza Fernanda pela sua competência e aproveita para oferecer uma promoção de cargo. $O$ cargo era justamente o de Karina, que é convidada a afastar-se temporariamente devido ao seu péssimo rendimento.

As profissões de destaque na ciedade, como médico, engenheiro

No entanto, vendo a alegria no rosto de Fernanda, Karina diz que prefere se demitir se não serve mais para a empresa. $O$ chefe diz não saber o porquê da 
mudança brusca da sua competência e diz não ter outra saída senão acatar o seu pedido. Assim, Karina se demite.

Com o fechamento da história, o apresentador-pastor retorna à tela e passa a explicar que a raiva desperta inveja. Segundo ele, se a pessoa que sentir a fúria da inveja não pertencer à "Vigília dos 318" poderá ser destruída, pois não possui proteção à inveja e aos trabalhos de feitiçaria.

Antes de fechar o bloco, ele faz uma ressalva:

"Portanto, evite, evite a queda. Venha buscar a Deus na vigília dos 318. Venha passar no santuário da fé. Inclusive, você que não entregou o envelope com seu pedido, traga-o! Pois vamos levá-lo ao vale do Gideão".

Mais uma vez, nota-se o grande nível de conhecimento que a cúpula dirigente da IURD possui sobre seu público e, antes de qualquer coisa, sobre a própria cultura brasileira. MELO (1988) e MARTíN-BARBERO (2003) indicaram em suas pesquisas a importância que as telenovelas possuem na construção do imaginário dos povos latino-americanos, híbridos e audiovisuais por essência. Sabendo disso, os dirigentes da IURD exploram ao máximo a teledramaturgia em seus programas, transformando-os numa atração interessante não só para os seguidores da IURD, mas também para pessoas de vários credos. Não é por acaso que ROCHA tenha dito que os programas religiosos transmitidos na Rede Record sejam "feitos para telespectadores e não para fiéis" (1998:126).

\section{protagonismo discreto do bispo Edir Macedo}

Ao contrário de seu cunhado e concorrente no mercado neopentecostal da fé, o auto-intitulado missionário R. R. Soares, da Igreja Internacional da Graça de Deus, o bispo Edir Macedo aparece esporadicamente na programação da IURD, apesar de a influência central de seu pensamento e de seu próprio comportamento notar-se em todas as etapas do programa.

Um exemplo visível do seu controle sobre o conteúdo que é veiculado no programa é a entonação usada pelos pastores e a comunicação corporal utilizada. Numa parte do programa, em que durante dez minutos a cúpula da IURD discute trechos da Bíblia e relaciona as atitudes dos profetas à vida cotidiana e as deles mesmos, eles procuram utilizar as mesmas expressões proferidas por Edir Macedo em seus cultos e contidas na literatura assinada pelo bispo, como na polêmica obra "Orixás, Caboclos \& Guias: deuses ou demônios?", em que MACEDO profere uma frase muito utilizada nas introduções dos programas televisivos da IURD: "Temos ministrado o Evangelho de Jesus Cristo na sua pureza e integridade (...)” (2002: 9).

Sempre que são apresentadas histórias bíblicas como fundo temático das cerimônias religiosas, um quadro educativo apresentado pelo bispo Edir Macedo é introduzido na programação. Na semana em que foi feita a observação do programa, por exemplo, a IURD celebrava a "Fogueira Santa na Fé de Gideão". Com um discurso inflamado, o bispo Edir Macedo aparece com roupa de frio diante de uma fogueira queimando pedaços de papéis - que, segundo eles, são os pedidos das pessoas. Para legitimar o seu discurso, ouve-se em segundo plano a tradução do seu discurso em hebraico, uma voz idêntica à voz do personagem Jesus Cristo do polêmico filme do diretor norte-americano Mel Gibson. Aliás, o uso de produtos da Indústria Cultural como um instrumento popular de legitimação é uma das características dos programas da IURD (DANTAS, 2007). 
Num quadro chamado "Momento de reflexão com Edir Macedo", o próprio aparece vestido elegantemente à frente de centenas de livros expostos disciplinarmente numa gigantesca estante e explica o lado psicológico de Gideão - como se o conhecesse intimamente. Ao final, em tom de ameaça, afirma que, se o indivíduo quer ser racional diante de Deus, este não o escutará, pois a fé vem do coração, é emoção.

\title{
A bênção final (O copo com água)
}

Após vários quadros e uma repetição incessante de idéias de fé, cura, libertação e vitória, o apresentador-pastor anuncia que chegou a hora de falar com Deus. Após ajoelhar-se em círculo na companhia de mais quatro pastores, ele inicia sua oração suplicando a atenção de Deus, em lágrimas:

\footnotetext{
"Senhor nosso Deus, Nosso Pai, nós estamos aqui diante de ti, de joelhos, Meu Pai. Nós sabemos que mudarás a história desse povo. Talvez, Meu Pai, essas pessoas que estão em casa estão possuídas pelo Demônio, Meu Pai. Traz teus anjos com espada de fogo para repreender essas forças malignas. Ó Meu Deus, ela vai entrar e vai vencer o Diabo, porque - Meu Deus - quem agrada ao Senhor muda sua história, Meu Pai”.
}

Após calar-se durante poucos segundos, um outro pastor intervém e diz:

\begin{abstract}
"Sim, Meu Deus, em nome do Senhor Jesus, Meu Pai, as pessoas que vão entrar no santuário hoje aguardam tua resposta, Meu Pai. Elas estão fazendo coisas que ficarão na tua dependência, Meu Pai. Tem Piedade, Meu Pai! Em nome do Senhor, consagre esse santuário, Meu Pai. Faz com que essa pessoa - Meu Deus - veja na vida dela o que nunca viu, o que humanamente nunca ela viu. Arranca, Meu Deus, a opressão, Meu Pai. Retira Satanás da vida dela. Em nome do Senhor Jesus, consagre as trombetas que vamos tocar hoje, em nome de Jesus".
\end{abstract}

E, para finalizar, num tom ainda mais emocional, um outro religioso diz:

"Meu Deus, para concordarmos acerca de qualquer coisa da terra, é concordar contigo, meu Pai. Meu Deus, abençoa este copo de água e consagra mais uma vez esse santuário. Foi um esforço grande chegar até tua presença. Em nome de Jesus, mais uma oração a ti, Meu Pai. Em nome de Jesus, Amem!".

\section{Conclusōes}

Como se pôde perceber nesta breve análise de um programa religioso vespertino, a IURD conseguiu um espaço de destaque no cenário religioso nacional não apenas pelo carisma de seu líder, mas também por sua grande habilidade em identificar e suprir as necessidades do brasileiro que mora nas periferias dos grandes centros urbanos e a utilização inteligente dos meios de comunicação de massa, sobretudo da televisão - que requer um alto grau de profissionalismo.

Seus programas possuem a "salvação" como tema central, mas se subdividem em vários blocos de atrações, como uma revista eletrônica, e é justamente aí que está seu mérito: hibridizar ao máximo sua programação, para conquistar novos adeptos e até uma audiência laica, preocupada apenas em entreter-se. Edir Macedo e sua equipe de profissionais da comunicação convertem (eficazmente) a religião em produto midiático de grande aceitação, pois os amantes da telenovela "mexicanizada", da dramaturgia global, dos talk-shows, dos debates temáticos e das atrações grotescas vão encontrar nos programas da IURD, pelo menos, uma atração que lhes interessa. 
ASSMANN, Hugo (1986). A igreja eletrônica e seu impacto na América Latina. Petrópolis: Vozes.

DANTAS, José Guibson (2006). Dinheiro: o passaporte para a graça - um estudo sobre as representações sociais do dinheiro no programa "Show da Fé”. Recife: Ed. do Autor.

(2007). Neopentecostais e as mediações culturais: o comportamento dos telespectadores diante dos programas televisivos das igrejas neopentecostais. Recife: Livrorápido.

DURKHEIM, Émile (2003). As formas elementares da vida religiosa. 2.ed. São Paulo: Paulus.

HOLT, Douglas B. (2005). Como as marcas se tornam ícones: os princípios do branding cultural. São Paulo: Cultrix.

JUSTINO, Mário (2002). Nos bastidores da Universal: a vida secreta na Igreja Universal do Reino de Deus. São Paulo: Geração.

MACEDO, Edir (2000). Orixás, caboclos \& guias: deuses ou demônios? Rio de Janeiro: Universal.

MACHADO, Márcia Benetti (2004). Sagração e consagração do sujeito: a televisão confere existência aos "escolhidos" da Igreja Universal do Reino de Deus. In: GRUSZYNSKI, Ana Cláudia et al. (orgs.). Comunicação e práticas culturais. Porto Alegre: UFRGS.

MARCCAL NETO, Vulmeron Borges (2003). A propaganda nazista: seus instrumentos e estratégias. São Paulo, 2003, 79p. Monografia (Gestão estratégica em comunicação organizacional e relaçōes públicas) - Escola de Comunicação e Artes, Universidade de São Paulo.

MARTIN-BARBERO, Jesús (2003). Dos meios às mediações. Rio de Janeiro: UFR.

MARTIN-BARBERO, Jesús; REY, Germán (2001). Os exercícios do ver: hegemonia áudiovisual e ficção televisiva. São Paulo: Senac.

MELO, José Marques de (1988). As telenovelas da Globo: Produção e exportação. São Paulo: Summus.

OLIVEIRA, Ivo Xavier de (2003). Igreja Universal do Reino de Deus - uma instituição inculturada. São Paulo: Pulsar.

ORO, Ivo Pedro (1996). O outro é o demônio: uma análise sociológica do fundamentalismo. São Paulo: Paulus.

ROCHA, Penha (1998). A globalização da Igreja Universal do Reino de Deus: TV Record e Family Channel. In: RUBIM, Antônio Albino Canelas; BENTZ, lone Maria Ghislene; PINTO, Milton José (orgs.). Produção e recepção dos sentidos midiáticos. Petrópolis: Vozes.

UNESCO (1983). Um mundo e muitas vozes: comunicação e informação na nossa época. Rio de Janeiro: Ed. da Fundação Getúlio Vargas. 